\title{
Inhibition of methanogenesis by tea saponin and tea saponin plus disodium fumarate in sheep*
}

\author{
Z.P. Yuan, C.M. Zhang, L. Zhou, C.X. Zou, Y.Q. Guo, \\ W.T. Li, J.X. Liu ${ }^{1}$ and Y.M. Wu \\ College of Animal Sciences, Ministry of Education, \\ Key Laboratory of Molecular Animal Nutrition, Zhejiang University \\ Hangzhou 310029, P.R. China
}

\begin{abstract}
The study was conducted to investigate the effects of tea saponin (TS $5 \mathrm{~g} / \mathrm{kg} \mathrm{DM}$ ), TS plus disodium fumarate (DF $20 \mathrm{~g} / \mathrm{kg} \mathrm{DM}$ ) and coconut oil (7\% DM) on methane emissions in sheep using simple box chamber. Eight Huzhou sheep were assigned to four treatments in a $4 \times 4$ Latin square arrangement. Addition of TS and TSDF decreased $(\mathrm{P}<0.0001)$ methane emissions by 8.5 and $9.6 \%$, respectively. Addition of TSDF significantly increased $(\mathrm{P}<0.01)$ propionate and decreased $(\mathrm{P}<0.01)$ acetate proportion. Addition of TS and TSDF, though not as effectively as coconut oil, can inhibit methane emissions, which is beneficial for economy and environment.
\end{abstract}

KEY WORDS: tea saponin, fumarate, coconut oil, methane emission, sheep

\section{INTRODUCTION}

Livestock is one of the largest sources of methane emission with 80-115 million tons produced per year, equivalent to $15-20 \%$ of total anthropogenic methane (IPCC, 2001). Methane produced during ruminal fermentation represents a loss of $2-12 \%$ of gross energy intake (Johnson and Johnson, 1995). Inhibition of methane can represent an improvement in feed efficiency and short-term economic and long-term environmental benefits.

Attempts to reduce methanogenesis by the addition of chemicals, such as halogen compounds and ionophores, have long been made. Ionophores, such as monensin and lasalocid, have especially been put to practical use. However,

\footnotetext{
* Supported partly by the National Natural Science foundation of China, Grant No. 30530560, and Co-ordinated Research Projects from Joint FAO/IAEA Division, IAEA, No. 12665/R0

${ }^{1}$ Corresponding author: email: liujx@zju.edu.cn
} 
these ionophores may depress fibre digestion (Guan et al., 2006). Because one of the greatest merits of ruminants is the ability to utilize fibre, methane production should be reduced without depressing fibre digestion. Consequently, proper compounds are needed to overcome these problems. Fumarate has been shown to be an effective substance to suppress the methanogenesis (Asanuma et al., 1999), and tea saponin (TS) has a beneficial effect in vitro (Hu et al., 2005).

However, it can be expected that the methane-suppressing effects of TS may lead to the accumulation of hydrogen (Hu et al., 2005), which may be solved by addition of fumarate, since hydrogen can be sunk when fumarate is reduced to succinate (Newbold et al., 2005). In this study, we investigated the effect of TS and TS plus disodium fumarate (DF) on methane emissions in sheep using simple box chamber. Coconut oil has been demonstrated to be an effective methane inhibitor (Machmüller et al., 2003a), and was used as positive control in the present study.

\section{MATERIAL AND METHODS}

\section{Animals, feeds and experimental design}

Eight sheep were randomly paired 4 fistulated and 4 not fistulated. A sheep was fed a basal diet of $600 \mathrm{~g}$ lucerne hay plus $400 \mathrm{~g}$ concentrate mixture (as is basis, $\%$ : maize 55.8, soyabean meal 15.8, wheat 15.8 , rapeseed meal 12.6) per day. Four treatments were designed with different additives: 1 . no additive (control), 2. TS ( $5 \mathrm{~g} / \mathrm{d}), 3$. TSDF (TS, $5 \mathrm{~g} / \mathrm{d}$ plus DF, $20 \mathrm{~g} / \mathrm{d})$ and 4 . coconut oil (7\% of the DM ). The adding level of TS was based on the previous work (Hu et al., 2005). The basal diet was fed in control, TS and TSDF, but the diet with coconut oil was adjusted to obtain the same levels of metabolizable energy and crude protein as the other three treatments, because of the high energy content in coconut oil. In this diet, maize was reduced to $12.2 \%$ of the whole diet. Chemical composition of two diets is shown in Table 1. The diets were given in equal portions twice a day at 08.30 and 16.30 . The sheep had free access to water.

Table 1. Chemical composition (DM basis) of the diet used in experiment

\begin{tabular}{lcc}
\hline \multirow{2}{*}{ Chemical composition, g/kg DM } & \multicolumn{2}{c}{ Diet } \\
\cline { 2 - 3 } & control ${ }^{1}$ & cocount oil \\
\hline $\mathrm{CP}(6.25 \times \mathrm{N})$ & 944 & 942 \\
$\mathrm{NDF}$ & 13.83 & 13.83 \\
$\mathrm{ADF}$ & 436 & 432 \\
$\mathrm{Ca}$ & 225 & 225 \\
$\mathrm{P}$ & 8.8 & 8.8 \\
$\mathrm{DE}, \mathrm{MJ} / \mathrm{kg} \mathrm{DM}$ & 6.8 & 6.8 \\
\hline
\end{tabular}

${ }^{1} \mathrm{TS}$ and TSDS 
Four pairs of sheep were randomly assigned to four treatments in a double $4 \times 4$ Latin square design. Each period lasted 21 days. Because only two chambers $(2.4 \times 1.6 \times 1.5 \mathrm{~m})$ were available, two pairs of animals were used at the same time. Before the morning feeding on $\mathrm{d} 15$, the first two pairs of sheep were moved to one of chambers for measurements of methane. The first day within the chambers was considered as adaptation period, allowing the sheep to adapt before measurements were recorded for two consecutive days starting at 08.00 in the morning. In the morning of the $\mathrm{d} 18$, another two pairs of sheep were used for measurements. When not used for methane measurements in chambers, animals were kept in individual pens.

\section{Sampling procedures and measurements}

During the two consecutive days when the sheep were housed in chambers, air sample was taken per hour from the exhaust pipe of each chamber with an airproof syringe, the volume of the air flowed through the chamber was recorded, and then the air sample was analysed for methane concentration by gas chromatograph (GC2100, Shimadzu) equipped with a Flame Ionization detector (FID) (Hu et al., 2005). After the sheep were removed from the chambers, rumen fluid samples were taken from the rumen cannulated sheep before the morning feeding, using a tube via the fistula. Immediately after collection, rumen fluid samples were strained through four layers of compress gauze. The $\mathrm{pH}$ of rumen liquor was determined immediately after removal using a $\mathrm{pH}$ meter (Model PB-20, Sartorius). Volatile fatty acids (VFA) were analysed using gas chromatography (GC-2100, Shimadzu). Samples were injected into a $2 \mathrm{~m} \times 3 \mathrm{~mm}$ glass column packed with Porapak Q ( $80 \mathrm{mesh})$. Nitrogen was used as a carrier. The details were described elsewhere (Hu et al., 2005).

\section{Statistical analysis}

The results were analysed according to Latin square design for the effect of diet $(\mathrm{n}=4)$, period $(\mathrm{n}=4)$ and animal $(\mathrm{n}=4)$ on methane emissions (SAS version 8.0). Multiple comparisons among means were carried out by the Duncan's multiple range test.

\section{RESULTS}

Addition of TS, TSDF and coconut oil resulted in similar diurnal pattern of methane emissions as control (Figure 1). Methane emissions were rapidly increased 


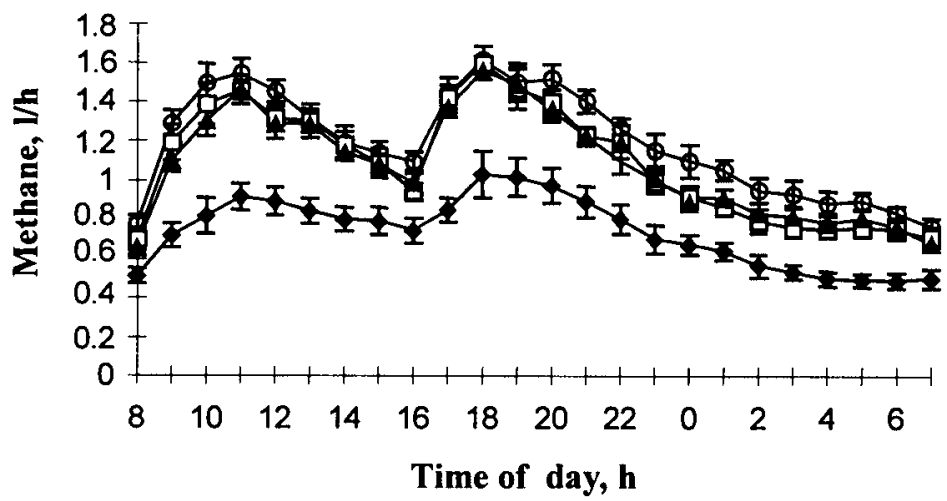

Figure 1. Diurnal pattern of methane emissions from sheep in a chamber fed diets with different additives: control (-०-, no additive), tea saponin (- - -, TS 5g/kg DM), tea saponin plus disodium fumarate (- $\mathbf{\Delta -}, \mathrm{TS}, 5 \mathrm{~g} / \mathrm{kg}$ DM plus DF, $20 \mathrm{~g} / \mathrm{kg} \mathrm{DM})$ and coconut oil (-,$- 7 \% \mathrm{DM})$. The vertical bars indicate standard error of mean at selected times

to maximum 2-3 $\mathrm{h}$ after the animals were fed, and then decreased slowly until the next feeding. The diets with neither TS nor TSDF have effects $(\mathrm{P}>0.05)$ on methane emissions in daytime, but methane emissions were significantly decreased $(\mathrm{P}<0.001)$ at night.

There was little difference in dry matter intake (not shown) through the experiment, because restricted feeding was adopted for all sheep. Methane emission was reduced $(\mathrm{P}<0.001)$ by all the additives, with little difference between TS and TSDF (Table 2).

Table 2. Ruminal $\mathrm{pH}$ and volatile fatty acids (VFAs) variables for sheep fed diets with out or with tea saponin (TS), TS plus disodium fumarate (TSDF) or coconut oil

\begin{tabular}{lcccccc}
\hline Item & Control & TS & TSDF & $\begin{array}{c}\text { Coconut } \\
\text { oil }\end{array}$ & SEM & P-value \\
\hline Methane, 1/kg of DMI & $28.7^{\mathrm{a}}$ & $26.2^{\mathrm{b}}$ & $25.9^{\mathrm{b}}$ & $17.7^{\mathrm{c}}$ & 0.57 & $<0.0001$ \\
Ruminal pH & $6.82^{\mathrm{ab}}$ & $6.60^{\mathrm{c}}$ & $6.91^{\mathrm{a}}$ & $6.69^{\mathrm{bc}}$ & 0.06 & 0.04 \\
Total VFAs, mmol & 52.7 & 52.0 & 55.6 & 50.4 & 2.87 & 0.66 \\
Molar proportions, $\%$ & & & & & & \\
$\quad$ & & & & & & \\
$\quad$ acetate & $69.6^{\mathrm{ab}}$ & $68.4^{\mathrm{b}}$ & $65.2^{\mathrm{c}}$ & $71.1^{\mathrm{a}}$ & 0.72 & 0.006 \\
$\quad$ propionate & $22.0^{\mathrm{b}}$ & $22.3^{\mathrm{b}}$ & $26.3^{\mathrm{a}}$ & $21.8^{\mathrm{b}}$ & 0.55 & 0.003 \\
$\quad$ butyrate & $8.4^{\mathrm{a}}$ & $9.3^{\mathrm{a}}$ & $8.5^{\mathrm{a}}$ & $7.2^{\mathrm{b}}$ & 0.28 & 0.001 \\
Acetate: propionate & $3.18^{\mathrm{a}}$ & $3.7^{\mathrm{a}}$ & $2.48^{\mathrm{b}}$ & $3.27^{\mathrm{a}}$ & 0.11 & 0.007 \\
\hline
\end{tabular}

a,b,c within a row, means without a common superscript letter differ, $\mathrm{P}<0.05$

Compared with the control, ruminal $\mathrm{pH}$ was decreased by addition of TS $(\mathrm{P}<0.05)$, but not by TSDF and coconut oil $(\mathrm{P}>0.05)$ (Table 2$)$. Although there were 
no significant differences in total VFAs concentrations among diets, proportions of individual VFAs differed $(\mathrm{P}<0.01)$. Addition of TS had no significant effects on VFAs. Fumarate addition resulted in a significant increase $(\mathrm{P}<0.01)$ in propionate and a significant decrease in acetate production, but did not affect butyrate production. Addition of coconut oil showed no effects on the concentrations of acetate and propionate, but the concentrations of butyrate were significantly reduced $(\mathrm{P}<0.01)$.

\section{DISCUSSION}

In current study, TS addition reduced methane emissions by $8.5 \%$, lower than that obtained with approximately the same dose in vitro (Hu et al., 2005). The lesser extent may be due to the flow of liquid through the rumen, which may dilute the concentrations of TS. The methane-suppressing effects of saponin were presumably a direct action against the rumen microbes involved in methane formation, including methanogens and protozoa (Finlay et al., 1994). It is presumably that the methane-suppressing effects of TS may lead to accumulations of hydrogen (Hu et al., 2005). Another way of diverting hydrogen away from methane formation would be to promote alternative electron-sink metabolic pathways to dispose of the reducing power (Ungerfeld et al., 2003), and fumarate has been shown to compete successfully for hydrogen (Newbold et al., 2005). However, further addition of DF did not have better inhibitory effects on methane emissions compared to TS addition only. In the Rusitec, $6.25 \mathrm{mmol}$ fumarate caused a $1.2 \mathrm{mmol}$ fall in methane (Lopez et al., 1998). In the current study, daily methane emissions were reduced about $0.45 \mathrm{~mol}$ by addition of TSDF in a chamber, so if DF only, almost $2 \mathrm{~mol}$ (more than $300 \mathrm{~g}$ ) fumarate is needed. However, the daily dose of fumarate was $20 \mathrm{~g} / \mathrm{d}$ per sheep. Consequently, the contribution of fumarate on methane inhibition is limited in this study. Fumarate would be impractical as a means of eliminating methane emissions in vivo. Newbold et al. (2005) concluded that although it might be possible to use organic acids, and fumarate in particular, to decrease ruminal methane production, the quantities required to make a major impact on daily methane production might be impractical.

Methane emissions increased rapidly after the animals were fed, and thereafter decreased slowly. The diets with neither TS nor TSDF have effects $(\mathrm{P}>0.05)$ on methane emissions in daytime, but methane emissions decreased significantly $(\mathrm{P}<0.001)$ at night. Machmüller et al. (2003b) also observed similar diurnal pattern, which may be associated with the difference in animal activity and digestion between daytime and night. Further study is needed to clarify this.

Addition of TS reduced the final $\mathrm{pH}$ in rumen. Hu et al. (2005) obtained the same result in vitro. Asanuma et al. (1999) concluded that if fumarate is added to ruminant 
feed, its sodium salt should be used because fumaric acid decreases ruminal $\mathrm{pH}$. In current study, addition of DF avoided the decrease in $\mathrm{pH}$ in vivo. In effect, the sodium moiety serves as an agent to raise $\mathrm{pH}$, which is similar to the effect of the addition of sodium bicarbonate. Addition of TS had no significant effects on VFAs, suggesting that TS had minor effect on the pattern of rumen fermentation. Hu et al. (2005) obtained similar results in vitro. Addition of TSDF decreased acetate concentration, but propionate was significantly increased, which may be at the expense of acetate. Newbold et al. (2005) found that both fumarate and malate are key intermediates in the succinate-propionate pathway, in which malate is dehydrated to fumarate and fumarate reduced to succinate, which is then decarboxylated to propionate.

\section{CONCLUSIONS}

Addition of tea saponin (TS) reduced methane emissions, while further addition of disodium fumarate (DF) did not enhance the effects. Addition of TS did not significantly influence the VFAs, while addition of TSDF had a better effect on acetate : propionate. Consequently, combination of TS and DF has additional effects on both rumen fermentation and methane emissions.

\section{REFERENCES}

Asanuma N., Miwa I., Tsuneo H., 1999. Effect of the addition of fumarate on methane production by ruminal microorganisms in vitro. J. Anim. Sci. 82, 780-787

Finlay B.J., Esteban G., Clarke K.J., Williams A.G., Embley T.M., Hirt R.P., 1994. Some rumen ciliates have endosymbiotic methanogens. FEMS Microbiol. Lett. 117, 157-162

Guan H., Wittenberg K.M., Ominski K.H., Krause D.O., 2006. Efficacy of ionophores in cattle diets for mitigation of enteric methane. J. Anim. Sci. 84, 1896-1906

Hu W.L., Liu J.X., Ye J.A., Wu Y.M., Guo Y.Q., 2005. Effect of tea saponin on rumen fermentation in vitro. Anim. Feed Sci. Tech. 120, 333-339

IPCC (Intergoverment Panel on Climate Change), 2001. Climate Change 2001. The Scientific Basis. Cambridge University Press, Cambridge (UK)

Johnson K.A., Johnson D.E., 1995. Methane emissions from cattle. J. Anim. Sci. 73, 2483-2492

Lopez S., Valdes C., Newbold C.J., Wallace R.J., 1998. Influence of sodium fumarate addition on rumen fermentation in vitro. Brit. J. Nutr. 81, 56-64

Machmüller A., Soliva C.R., Kreuzer M., 2003a. Effect of coconut oil and defaunation treatment on methanogenesis in sheep. Reprod. Nutr. Develop. 43, 41-45

Machmüller A., Soliva C.R., Kreuzer M., 2003b. Methane-suppressing effect of myristic acid in sheep as affected by dietary calcium and forage proportion. Brit. J. Nutr. 90, 529-540

Newbold C.J., Lopez S., Nelson N., Ouda J.O., Wallace R.J., Moss A.R., 2005. Propionate precursors and other metabolic intermediates as possible alternative electron acceptors to methanogenesis in ruminal fermentation in vitro. Brit. J. Nutr. 94, 27-35

Ungerfeld E.M., Rust S.R., Burnett R., 2003. Use of some novel alternative electron sinks to inhibit ruminal methanogenesis. Reprod. Nutr. Develop. 43, 189-202 